\title{
Opportunities for inhaler device selection in elderly patients with asthma or COPD
}

Patient Intelligence

4 December 2015

Number of times this article has been viewed

\author{
Robert Barrons' \\ James Wheeler ${ }^{2}$ \\ J Andrew Woods' \\ 'Wingate University School of \\ Pharmacy, Wingate, NC, USA; \\ ${ }^{2}$ University of Tennessee Health \\ Science Center, Nashville, TN, USA
}

Correspondence: Robert Barrons

Wingate University School of Pharmacy,

316 North Main Street, Wingate,

NC 28I74, USA

Tel +| 704233836 |

Email rbarrons@wingate.edu
Abstract: An anticipated surge in the elderly population will be accompanied by a rise in aging patients with asthma or COPD. Clinician selection of inhalers needs to address the unique challenges to elderly patients. These challenges to the use of inhalers include diminished physical and cognitive abilities, as well as cost reimbursement issues associated with polypharmacy and the Medicare gap. Clinicians should consider patient preferences for an inhaler device that provides ease of administration, and addresses conveniences such as portability, visual, and auditory indicators of dosing completion. The addition of spacer devices resolves hand-breath coordination difficulty with pressurized metered dose inhalers, but reduces overall inhaler convenience. Soft mist inhalers $\left(\right.$ Respimat $^{\mathbb{R}}$ ) improve ease of administration, but use may be limited by cost and formulary availability. Multiple dose dry powder inhalers provide convenience and simplified use by requiring only one to two steps prior to administration, but concerns of peak inspiratory flow requirements remain among patients with advanced age and severity of COPD. If unaddressed, these challenges to inhaler selection contribute to inappropriate use of inhalers in $41 \%$ to $69 \%$ of patients, accompanied by at least $51 \%$ non-adherence to treatment. Clinicians must first avail themselves of reputable educational resources regarding new inhaler developments and administration, for competent patient instruction. Patient education should include a checklist of inhaler technique, with physical demonstration of each device by the patient and provider. Device demonstration significantly improves inhaler technique and identifies the need for nebulization therapy. Clinician and patient knowledge of available inhalers and their administration should initiate shared decision-making involving patient and provider medication preferences and choices. Patient education and shared decision-making should be longstanding and opportunistic, addressing failed inhaler adherence in the outpatient setting, and the contribution of inhaler non-adherence to hospital admissions and emergency department visits.

Keywords: elderly patients, asthma, COPD, non-adherence, patient education, inhaler

\section{Introduction}

COPD is a progressive disorder of airway limitation often undiagnosed until evidence of severe disease. Advanced staging of COPD from latent detection results in a greater frequency and severity of exacerbations most commonly seen in elderly patients, individuals greater than 65 years old. ${ }^{1}$ Asthma is a chronic inflammatory disease of the airways exhibiting greater mortality, hospitalizations, and emergency department visits among the elderly. ${ }^{2,3}$ In the USA, COPD currently ranks as the third leading cause of overall mortality, with 377 patient deaths daily, compared to nine patient deaths daily associated with asthma. ${ }^{4}$ Acute disease exacerbations contribute significantly to these mortalities, ${ }^{1,5}$ while chronic symptoms compromise the ability to work and exercise, and overall quality of life. ${ }^{6}$ 
Therapeutic goals for patients with asthma or COPD are to reduce the frequency and severity of disease exacerbations, while improving tolerance to daily activities. ${ }^{1}$ Inhalation therapies remain central to treatment providing effective pulmonary concentrations, duration of action, a rapid onset, while minimizing systemic adverse effects. ${ }^{7}$ Administration of aerosolized medication is reliant on four delivery devices, the pressurized metered dose inhaler (pMDI), the soft mist inhaler (SMI), the dry powder inhaler (DPI), and nebulization.

As aerosolized medications are dependent on deposition airways for local effects, errors to inhalation technique may significantly jeopardize therapy outcomes. Brocklebank et al reviewed 28 clinical trials assessing appropriate use of inhaler devices, and found $53 \%$ of patients using a DPI, $23 \%$ of pMDI alone, and $57 \%$ of pMDI with spacers, were without mistakes in inhaler technique. ${ }^{8}$ However, misuse of inhalers represents only one of three types of medication non-adherence that include underuse of inhalers, seen with infrequent use or absence of controller medications, ${ }^{9}$ and overuse of inhalers, commonly seen in periods of respiratory distress. ${ }^{10}$

Medication non-adherence is complicated by a deluge of inhaler devices resulting in confusing choices for clinicians and patients. Randomized controlled trials in patients with asthma and COPD found equivalent efficacy between pMDI, DPI, and nebulizers in clinical settings ${ }^{7,8}$ However, patient enrollment in these studies was insufficient to detect differences in outcomes, while exclusion of patients with poor inhalation technique made results difficult to translate into practice. ${ }^{7,8}$ Addressing the multitude of inhaler options and sources of non-adherence, current guidelines recommend several patient and device considerations in selection of an inhaler. ${ }^{1,7,11}$ Patient considerations include the capacity to use the device and preferences for a specific type of inhaler. Device considerations involve cost, reimbursement, and medication availability regarding specific inhalers. ${ }^{1,7,11}$ Attention to these factors should improve adherence to inhaler medications as they account for patient behavior, abilities, and allow patient participation in decisions to optimize therapy outcomes (Figure 1).

The goals of the manuscript are to examination elderly patient comorbidities impacting on inhaler selection, assess the types of inhaler devices and features that may enhance and impede patient adherence, and evaluate methods to address challenges to inhaler device education and adherence.

\section{Patient abilities}

By 2050, the proportion of individuals over age 65 in the USA is projected to nearly double, with those greater than
85 years of age representing the largest growing age group. ${ }^{12}$ With increased longevity, elderly patients with asthma and COPD face greater physical and cognitive co-morbidities that affect their ability to use inhaler devices. Age-related conditions that impact cognitive abilities include dementia, stroke, depression, and chronic hypercapnia and hypoxia which are common in end stage COPD. In patient ages 76 to 94, Allen and Ragab demonstrated mini mental status scores of $<24$ (cognitive impairment) correlated with incompetent use of an inhaler device. ${ }^{13}$

Additionally, patients with mild cognitive dysfunction (ie, mini mental status score of 23) may be unable to learn or retain techniques necessary for effective administration of pMDI or DPI devices. ${ }^{13,14}$ If medical findings warrant concern, elderly patients should be tested for cognitive competency prior to selection of inhaler devices.

Physical challenges to aging may involve rheumatologic and neurologic conditions such as arthritic ailments, Parkinson's disease, as well as visual and auditory deficits, that may impede device instruction. In patients with a mean age of 69 , Gray et al found insufficient hand strength (as measured with

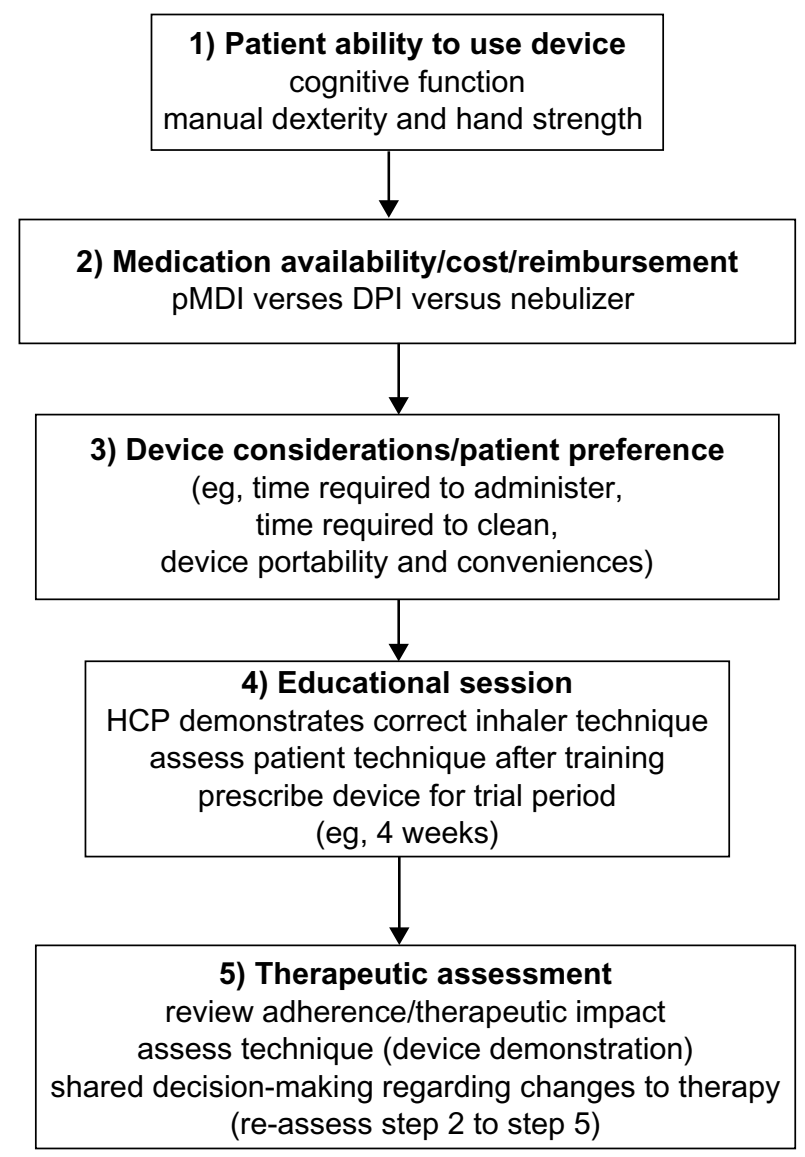

Figure I Algorithm for inhaler selection in elderly patients with asthma/COPD. Abbreviations: pMDI, pressurized metered dose inhaler; DPI, dry powder inhaler; $\mathrm{HCP}$, health care provider. 
a dynamometer) was a significant predictor of incorrect use of pMDI devices. ${ }^{15}$ Inadequate hand strength for inhaler device manipulation may be evident in up to one third of elderly patients. ${ }^{16}$ Physical limitations may lead to an inability to prime and actuate a pMDI or ready the powder content for inhalation in DPIs. Similarly, reductions in manual dexterity may compromise hand-mouth coordination technique and preparation of single dose devices needed with pMDIs and some DPIs, respectively. These constraints may be easily detected upon patient demonstration of each device. Such restrictions may be more evident in advanced staging of each condition and warrant assisted administration of aerosolized medication through use of nebulizers by trained individuals.

\section{Medication availability}

Aerosolized medications for asthma and COPD are categorized as rescue therapy, for treatment of acutely worsened symptoms, and controller medications, for management of daily symptoms and reducing the frequency and severity of disease exacerbations. Selection of an inhaler must account for the device availability of rescue and controller medications. Controller medications are available for administration through all inhaler devices (pMDI, DPI, nebulization, and SMI), while recent US Food and Drug Administration approval of ProAir ${ }^{\circledR}$ RespiClick (albuterol sulfate) has allowed multiple device availability (DPI, pMDI, nebulizers, and SMI) of rescue medications in the USA.

Dependent on patient abilities, cost, and preferences, therapy may involve two or more types of inhalers. However, use of the same type of device for all aerosolized medications has been recommended (ie, pMDI or nebulizer as rescue and controller therapy). ${ }^{7}$ Selection of a single inhaler format may assist with patient teaching, while reducing confusion from different inhalation techniques required by dissimilar devices. ${ }^{7}$ In a prospective cross-sectional observational study of 300 pulmonary clinic patients, Khassawneh et al found use of multiple inhalers was associated with significantly increased risk of incorrect handling of each device, when compared with use of a single inhaler. ${ }^{17}$

\section{Cost and reimbursement}

Between 1988 and 2010 in the USA, the proportion of elderly individuals taking at least five medications tripled to $39 \%,{ }^{18}$ in association with multiple morbidities. ${ }^{19,20}$ These increased medication needs develop at a time of reduced personal income resulting from occupational retirement. Among individuals with asthma and COPD, increased medication needs are accompanied by $51 \%$ to $60 \%$ therapy adherence. ${ }^{20-22}$
While multiple factors discussed in this review are contributory to non-adherence, cost and reimbursement strategies need consideration when selecting an inhaler device. ${ }^{7}$

In 2011 in the USA, 93\% of non-institutionalized elderly individuals received Medicare, with $30 \%$ of these recipients participating in Medicare Advantage. ${ }^{23}$ Introduced in 1965 , traditional Medicare coverage provides hospital insurance (Plan A), medical and preventative services (Plan B). Patients must be enrolled in Medicare Plans A and B to participate in Medicare Advantage (Plan C). Both traditional Medicare and Medicare Advantage offer a prescription drug plan (Plan D). ${ }^{24}$ Under Medicare's prescription drug coverage, the patient cycles through yearly cost-sharing provisions.

In the USA, Medicare's prescription drug coverage gap may place financial constraints on the elderly with multiple medication needs. For example, eight refills of just two controller medication inhalers such as Advair ${ }^{\circledR}$ Diskus $^{\circledR}$ $500 \mathrm{mcg} / 50 \mathrm{mcg}$ twice daily and Spiriva ${ }^{\circledR}$ Handihaler $^{\circledR}$, with a combined Medicare prescription drug plan patient cost of $\$ 260$ monthly, ${ }^{25}$ would reach $70 \%$ of medication allowances prior to reaching the coverage gap. Coverage gap cost related non-adherence may reduce use of brand dominated high cost medications, including inhaler devices, by $10 \%$ to $15 \% .{ }^{26}$ Nebulized medications and equipment costs are covered under Medicare Part B, assigning a co-payment of $20 \%$ (from contracted supplier) with device ownership after 13 months rental. ${ }^{24}$ The costs of a nebulizer (ie, jet nebulizer) is commonly less than $\$ 200$, while patient nebulized medication costs for combined controller medications (ie, Arformoterol + Budesonide) of approximately $\$ 60$ per month, may be a cost-effective alternative to pMDI and DPI devices. ${ }^{27}$ Fortunately, the Affordable Care Act of 2010 will close Medicare's medication coverage gap by 2020 . Until that date, yearly reductions of medication cost sharing from $45 \%$ to $25 \%$ (from 2015 to 2020), will continue to assist seniors, ${ }^{28}$ as pMDIs and DPIs become increasingly affordable.

\section{pMDls and SMls}

Pressurized metered dose inhalers (pMDIs) were the first type of inhalers brought to the market in the mid-1950s. They contain four parts: canister, metering valve, actuator, and use of a liquid propellant as both the power agent, as well as the suspending medium..$^{29}$ MDIs deliver finely divided aerosols containing drugs that are "respirable" in size, typically 5 $\mu \mathrm{m}$ or less. ${ }^{7}$ With the transition to newer hydrofluoroalkane (HFA) based propellants, some advantages were gained. Numerous HFA inhalers have a lower impact force and warmer aerosol temperature. These properties overcome the 
"cold freon" effect that may cause patients to stop inhaling the chlorofluorocarbon (CFC) powered dose delivery, leading to inconsistent or inadequate dose deposition into the lungs. In addition, the lower plume velocity and smaller particle size among HFA inhalers may allow for greater absorption of drug in the small airways. ${ }^{30}$ Since 2004 , pMDIs have increasingly introduced dosing counters to inform patients of refill needs. The small, portable size of pMDIs allows convenient transport and ready availability for administration of rescue medications during emergent symptoms. However, poor or inadequate inhalation skills have been documented in $8 \%$ to $59 \%$ of patients. ${ }^{31}$ McFadden reviewed 995 patients on use of pMDI and found the most common errors to inhalation technique included hand-lung discoordination (27\%), abbreviated or absent breath holding (26\%), and excessively rapid rate of inspiration (19\%). ${ }^{32}$ Patient failure to demonstrate slow inhalation technique is perhaps the most relevant of these steps, as breath holding and device coordination are less critical if inhalation is slow, with peak inspiratory flow (PIF) rates $<60 \mathrm{~L} / \mathrm{min}^{33}$

Inhaler spacers or valved-holding chambers (spaces with one-way inspiratory valve) address problems associated with hand-mouth coordination of pMDIs, allowing time and distance for dispersion an aerosolized medication into a respirable size. ${ }^{31}$ Additionally, spacer devices may provide audible feedback to encourage reduction in inspiratory flow rate, to further optimize lower airway deposition. ${ }^{34}$ Spacer devices for pMDIs should be considered in all elderly patients with chronic airway disease who demonstrate poor hand-mouth coordination for either rescue or controller medications. ${ }^{7}$ However, spacer devices add bulk to transportation, storage, and increase the time for assembly, reducing the overall conveniences inherent to the pMDI. In an observational study of 161 patients with obstructive airway disease, Sadowski et al found older patients using a pMDI with spacers demonstrated the poorest device acceptability, as compared with lone pMDI and DPI devices. ${ }^{35}$ Spacer "disuse" may result as patients demonstrate good technique in the clinic, yet contrive to ineffectively using the pMDI with spacers in routine practice. ${ }^{36}$

The newest inhaler product to the market are soft mist inhalers (SMIs). SMIs are mechanistically similar to nebulizers but offer the convenience and portability of an inhaler. Although a number of products are in development, the Respimat ${ }^{\circledR}$ (Boehringer Ingelheim $\mathrm{GmbH}$ and $\mathrm{Co} \mathrm{KG}$, Ingelheim, Germany) device is the only available US Food and Drug Administration approved SMI. Currently, tiotropium, albuterol/ipratropium, and olodaterol are medications available via Respimat ${ }^{\circledR}$ SMI delivery in the USA. The Respimat ${ }^{\circledR}$ SMI uses a tightened spring (from rotation of the device base) to generate the mechanical energy that forces a metered dose solution through channels to produce jets of liquid that converge to form a soft mist aerosol cloud. ${ }^{37}$ This soft mist exhibits at least one third the velocity of aerosol produced from a pMDI, while containing a free particle fraction (respiratory particles $<5.8 \mu \mathrm{m}$ ) nearly twice as high as the pMDI and DPI. ${ }^{37}$ As a result of these properties, Respimat SMI demonstrated significantly greater pulmonary delivery, while reducing oropharyngeal deposition. ${ }^{38}$ Although Respimat SMI still requires inhalation coordination following actuation, greater pulmonary drug availability further benefits patients with poor inhaler technique. ${ }^{39}$ Two large studies totaling 374 patients with obstructive airway disease, demonstrated significantly greater preference for Respimat SMI versus pMDI ( $83.7 \%$ versus $72.9 \%, P<0.001)$ and DPI devices $(80.2 \%$ versus $75.7 \%, P=0.001) .{ }^{40,41}$ However, high prices, at least four times more costly than albuterol pMDI, and limited drug formulary availability, have narrowed the Respimat SMI scope of practice (Table 1).

\section{DPIs}

Since its introduction in 1967, dry powder inhalers (DPIs) were developed in an effort to maintain the simplicity and convenience of a pMDI, while removing the reputed difficulty surrounding pMDI administration. ${ }^{42}$ Unlike the pMDI, the DPI is a passive breath activated device, dependent on patient inspiration for actuation, instead of the assistance of a propellant. DPI devices consist of a powdered drug formulation either in a pure form ${ }^{40}$ or paired with an inactive carrier, such as lactose. The powder drug formulation of micronized drug particles $(1-5 \mu \mathrm{m})$ combined with a larger excipient adds to product dosing stability. Patient inspiration must generate sufficient shear forces within the DPI, causing separation of drug particles from lactose, allowing medication dispersion. ${ }^{40,43}$ The resulting aerosolized medication should be of a respiratory particle size of $1-5 \mu \mathrm{m}$ in diameter to achieve optimal deposition in central, intermediate, and peripheral airways. The percentage of each dose within this optimal size for local respiratory effects is the fine particle fraction $(\mathrm{FPF}){ }^{44}$

The PIF is the patient inspiratory effort that results in formation of a FPF needed for desired therapeutic outcome. Most DPIs deliver a FPF of 20\%-40\%, resulting from an inhalation flow, or PIF, that produces a pressure drop of $4 \mathrm{kPa}$. The inhalation flow is dependent on the internal resistance of the DPI device. ${ }^{36,44}$ DPIs requiring a PIF of $<50 \mathrm{~L} / \mathrm{min}$ are 
Table I Inhaled medication and corresponding devices for asthma and COPD in the USA 2015

\begin{tabular}{|c|c|c|c|c|c|}
\hline \multirow[t]{2}{*}{ Medication category } & \multirow[t]{2}{*}{ Generic name } & \multirow[t]{2}{*}{ Brand name } & \multicolumn{3}{|c|}{ Device availability } \\
\hline & & & pMDI & DPI & Nebulizer SMI \\
\hline \multicolumn{6}{|l|}{ Beta agonist } \\
\hline \multirow[t]{5}{*}{ Short acting } & Albuterol & ProAir HFA ${ }^{\circledR}$, Proventil HFA ${ }^{\circledR}$, & $\checkmark$ & & \\
\hline & & Ventolin HFA ${ }^{\circledR}$ & $\checkmark$ & & \\
\hline & & ProAir ${ }^{\circledast}$ RespiClick & & $\checkmark \mathrm{M}$ & \\
\hline & Albuterol & Accuneb & & & $\checkmark$ \\
\hline & Levalbuterol & Xopenex $^{\circledR}$ & $\checkmark$ & & $\checkmark$ \\
\hline \multirow[t]{7}{*}{ Long acting } & Salmeterol & Serevent Diskus ${ }^{\circledR}$ & & $\checkmark M$ & \\
\hline & Salmeterol xinafoate & Serevent ${ }^{\circledR}$ & $\checkmark$ & & \\
\hline & Formoterol fumarate & Foradil Aerolizer ${ }^{\circledR}$ & & $\checkmark \mathrm{L}$ & \\
\hline & Formoterol fumarate & Perforomist Inhalation Solution ${ }^{\circledR}$ & & & $\checkmark$ \\
\hline & Arformoterol & Brovana Inhalation Solution & & & $\checkmark$ \\
\hline & Olodaterol & Striverdi Respimat & & & $\checkmark$ \\
\hline & Indacaterol & Arcapta Neohaler & & & $\checkmark$ \\
\hline \multicolumn{6}{|l|}{ Anticholinergics } \\
\hline Short acting & Ipratropium bromide & Atrovent $^{\circledR}$ & $\checkmark$ & & $\checkmark$ \\
\hline \multirow[t]{4}{*}{ Long acting } & Tiotropium & Spiriva Handihaler ${ }^{\circledast}$ & & $\checkmark^{\mathrm{H}}$ & $\checkmark$ \\
\hline & & Spiriva Respimat ${ }^{\circledR}$ & & & $\checkmark$ \\
\hline & Aclidinium & Tudorza ${ }^{\circledR}$ Pressair & & $\checkmark M$ & \\
\hline & Umeclidinium & Incruse Ellipta & & $\checkmark M$ & \\
\hline \multirow[t]{11}{*}{ Inhaled corticosteroids } & Budesonide & Pulmicort Respules ${ }^{\circledR}$ & & & $\checkmark$ \\
\hline & & Pulmicort Flexhaler & & $\checkmark$ & \\
\hline & Beclomethasone dipropionate & QVAR Inhalation Aerosol ${ }^{\circledR}$ & $\checkmark$ & & \\
\hline & Beclomethasone & Vanceril Inhalation Aerosol ${ }^{\circledR}$ & $\checkmark$ & & \\
\hline & Fluticasone propionate & Flovent HFA Inhalation Aerosol ${ }^{\circledR}$ & $\checkmark$ & & \\
\hline & & Flovent Diskus & & $\checkmark \mathrm{H}$ & \\
\hline & & Arnuity Ellipta & & $\checkmark^{M}$ & \\
\hline & Mometasone & Asmanex $^{\circledR}$ Twisthaler $^{\circledR}$ & & $\checkmark^{\mathrm{H}}$ & \\
\hline & Ciclesonide & Alvesco ${ }^{\circledR}$ & $\checkmark$ & & \\
\hline & Flunisolide & Aerobid-m ${ }^{\circledR}$, Aerobid $^{\circledR}$, & $\checkmark$ & & \\
\hline & & Aerospan & $\checkmark$ & & \\
\hline \multirow[t]{6}{*}{ Combination therapy } & Fluticasone + salmeterol & Advair ${ }^{\circledR}$ & & $\checkmark M$ & \\
\hline & Budesonide + formoterol & Symbicort $^{\circledR}$ & $\checkmark$ & & \\
\hline & Albuterol + ipratropium & Combivent $^{\circledR}$ Respimat $^{\circledR}$ & & & $\checkmark$ \\
\hline & Albuterol + ipratropium & DuoNeb Inhalation Solution ${ }^{\circledR}$ & & & $\checkmark$ \\
\hline & Mometasone + formoterol & Dulera $^{\circledR}$ & $\checkmark$ & & \\
\hline & Umeclidinium + vilanterol & Anoro Ellipta ${ }^{\circledR}$ & & $\checkmark \mathrm{M}$ & \\
\hline
\end{tabular}

Notes: Dry powder inhaler resistance to airflow: $\mathrm{H}=$ high resistance $\left(<50 \mathrm{~L} / \mathrm{min}_{\mathrm{PIF}}\right)$ : Spiriva Handihaler ${ }^{\circledR}$, Asmanex Twisthaler $^{\circledR}$, Pulmicort Flexhaler ${ }^{\circledR}$. $\mathrm{M}=$ medium resistance (50-90 L/min PIF): Anoro Ellipta ${ }^{\circledR}$, Advair Diskus ${ }^{\circledR}$, Arnuity Ellipta ${ }^{\circledR}$, Tudorza $^{\circledR}$ Pressair ${ }^{\circledR}$, Incruse Ellipta ${ }^{\circledR}$. L $=$ low resistance $\left(>90\right.$ L/min PIF): Foradil Aerolizer ${ }^{\circledR}$.

Abbreviations: PIF, peak inspiratory flow; DPI, dry powder inhaler; SMI, soft mist inhaler; pMDI, pressurized metered dose inhaler; HFA, hydrofluoroalkane.

high resistance, 50-90 L/min are medium-high to mediumlow resistance, while those needing an inspiratory flow rate $>90 \mathrm{~L} / \mathrm{min}$ are low resistance DPI devices. ${ }^{36}$

DPIs with high resistance produce higher FPFs at higher PIFs than low resistance devices, because they possess greater de-agglomeration forces, resulting in reduced oropharyngeal deposition and greater lung deposition. ${ }^{44}$ However, the clinical relevance of these findings is not known. ${ }^{36}$ While the vast majority of patients can achieve minimal PIF for high resistant DPIs (ie, Handihaler ${ }^{\circledR}$, Twisthaler $\left.{ }^{\circledR}\right)$, concerns remain regarding sufficient inspiratory capability among select patient populations. ${ }^{44}{ }^{46}$ Patients with advanced age and severity of COPD may not be able to achieve necessary PIF for high resistance devices. ${ }^{45,47}$ These individuals may be candidates for devices such as the In-Check Dial. Resembling a peak flow meter, the In-Check Dial mimics the resistance of specific DPI devices. Patient inspiration using the In-Check Dial identifies individual PIF abilities surrounding each DPI device. ${ }^{48}$ Alternatively, some DPIs provide a feedback system, such as an audible "click" or visible window color change, as seen with the Tudorza ${ }^{\circledR}$ Pressair $^{\circledR}$, to indicate dose delivery, while signifying sufficient PIF abilities. DPIs are available as single dose, which involve inhaling the contents of a capsule, and multiple 
Table 2 Inhaler conveniences and cost

\begin{tabular}{|c|c|c|c|c|}
\hline & Number of steps ${ }^{\wedge}$ & Dosing counter & Dosing prompt** & $\operatorname{Cost}^{\wedge \wedge \wedge}$ \\
\hline \multicolumn{5}{|l|}{ Dry powder inhaler } \\
\hline Albuterol (ProAir ${ }^{\circledR}$ RespiClick $^{\circledR}$ ) & I & Yes & Yes & $\$ \$$ \\
\hline Salmeterol (Serevent ${ }^{\circledR}$ Diskus $^{\circledR}$ ) & 2 & Yes & No & $\$ \$ \$$ \\
\hline Formoterol (Foradil Aerolizer $\left.{ }^{\circledR}\right)^{*}$ & 7 & No & Yes & $\$ \$$ \\
\hline Tiotropium (Spiriva $^{\circledR}$ Handihaler $\left.^{\circledR}\right)^{*}$ & 7 & No & Yes & $\$ \$ \$ \$$ \\
\hline Aclidinium (Tudorza ${ }^{\circledR}$ Pressair $^{\circledR}$ ) & 2 & Yes & Yes & $\$ \$ \$$ \\
\hline Umeclidinium (Incruse ${ }^{\circledR}$ Ellipta ${ }^{\circledR}$ ) & I & Yes & No & $\$ \$$ \\
\hline Budesonide (Pulmicort Flexhaler ${ }^{\circledR}$ ) & 3 & Yes & No & $\$ \$ \$$ \\
\hline Fluticasone $\left(\right.$ Flovent $^{\circledR}$ Diskus $^{\circledR}$ ) & 2 & Yes & No & $\$ \$ \$$ \\
\hline Fluticasone (Arnuity ${ }^{\circledR}$ Ellipta ${ }^{\circledR}$ ) & I & Yes & No & $\$ \$$ \\
\hline Mometasone $\left(\right.$ Asmanex ${ }^{\circledR}$ Twisthaler $^{\circledR}$ ) & 2 & Yes & No & $\$ \$ \$ \$$ \\
\hline Fluticasone + Salmeterol (Advair ${ }^{\circledR}$ Diskus $\left.^{\circledR}\right)$ & 2 & Yes & No & $\$ \$ \$$ \\
\hline Umeclidinium + Vilanterol $\left(\right.$ Anoro $^{\circledR}$ Ellipta $^{\circledR}$ ) & 1 & Yes & No & $\$ \$$ \\
\hline Pressurized metered dose inhalers & \multicolumn{4}{|l|}{ Number of steps ${ }^{\wedge \wedge}$} \\
\hline Albuterol (ProAir ${ }^{\circledR}$ HFA Ventolin HFA ${ }^{\circledR}$ ) & 4 & Yes & No & $\$$ \\
\hline Levalbuterol $\left(\right.$ Xopenex $\left.^{\circledR}\right)$ & 4 & No & No & $\$ \$$ \\
\hline Ipratropium (Atrovent ${ }^{\circledR}$ ) & 3 & Yes & No & $\$ \$ \$ \$$ \\
\hline Beclomethasone $\left(\mathrm{QVAR}^{\circledR}\right)\left(\right.$ Vanceri $\left.^{\circledR}\right)$ & 3 & Yes & No & $\$ \$$ \\
\hline Fluticasone (Flovent HFA ${ }^{\circledR}$ ) & 4 & Yes & No & $\$ \$ \$ \$$ \\
\hline Ciclesonide $\left(\right.$ Alvesco ${ }^{\circledR}$ ) & 3 & Yes & No & $\$ \$ \$ \$$ \\
\hline Flunisolide $\left(\right.$ Aerospan $\left.{ }^{\circledR}\right)$ & 4 & No & No & $\$ \$ \$$ \\
\hline Budesonide + Formoterol $\left(\right.$ Symbicort $\left.{ }^{\circledR}\right)$ & 4 & Yes & No & $\$ \$ \$ \$$ \\
\hline Mometasone + Formoterol $\left(\right.$ Dulera $\left.{ }^{\circledR}\right)$ & 4 & Yes & No & $\$ \$ \$ \$$ \\
\hline Soft mist inhalers & \multicolumn{4}{|l|}{ Number of steps } \\
\hline Albuterol + Ipratropium (Combivent Respimat ${ }^{\circledR}$ ) & 3 & Yes & No & $\$ \$ \$ \$$ \\
\hline Tiotropium (Spiriva ${ }^{\circledR}$ Respimat $^{\circledR}$ ) & 3 & Yes & No & $\$ \$ \$ \$$ \\
\hline Olodaterol (Striverdi ${ }^{\circledR}$ Respimat $^{\circledR}$ ) & 3 & Yes & No & $\$ \$$ \\
\hline
\end{tabular}

Notes: *Single dose DPI; **dosing prompt: visual or audible indicator of dosing completion; ^number of steps for preparation of DPI device: I) open device (expose mouthpiece - most devices); 2) expose mouthpiece (separate from device - as seen on Handihaler); 3 ) push capsule through foil (single dose device); 4) place capsule into capsule chamber (single dose device); 5) close mouthpiece (single dose device); 6) puncture capsule (single dose device) or blister pack (multiple dose device); 7) actuate device; $\wedge^{\wedge}$ number of steps for preparation of pMDI device (without spacer): I) shake device; 2) remove mouthpiece cover; 3 ) prime device (must determine need - device specific); 4) actuate device; ${ }^{\wedge \wedge}$ cost for single inhaler (average wholesale price): $\$:<\$ 50 ; \$ \$: \$ 50$ to $\$ 100 ; \$ \$$ : $\$ 100$ to $\$ 200 ; \$ \$ \$$ : $>\$ 200$. For $\geq 2$ medication strengths: average wholesale price was calculated among all formulations. Cost is in US\$.

Abbreviations: DPI, dry powder inhaler; pMDI, pressurized metered dose inhaler; HFA, hydrofluoroalkane.

dose devices, containing contents for inhalation within a blister package or a bulk reservoir. Single dose DPIs (eg, Handihaler $^{\circledR}$, Boehringer-Ingleheim, Aerolizer ${ }^{\circledR}$, Novartis International AG, Basel, Switzerland) are first generation inhalers, hampered by nuisances involving device preparation that may compromise patient adherence. Single dose devices require seven steps to ready the individual dosage for inhalation (Table 2). These steps include opening the capsule packaging and positioning the capsule within the device prior to each dosage. Multiple step device preparation may be difficult for many elderly, particularly patients with neuromuscular morbidities. Reports of patients ingesting capsules intended for the Handihaler ${ }^{\circledR}$ device, ${ }^{49}$ and need to refrigerate capsules prior to administration of the Foradil Aerolizer ${ }^{\circledR}$ DPI, further obstruct patient adherence. ${ }^{50}$

Multiple dose DPIs (ie, Diskus ${ }^{\circledR}$, GlaxoSmithKline plc [London, UK], Turbuhaler ${ }^{\circledR}$, AstraZeneca plc [London, UK]) commonly require only $2-3$ steps to prepare the device for inhalation (Table 2). In addition, multiple dose devices provide dosing counters that display refill needs, with audio (click) and/or visual indicators (color) to assure patients of device readiness and completion of inhalation (Table 2). Some hand strength and dexterity is required for dosage preparation of a DPI. However, greater concerns exist regarding activation of the inhaler, with exposure of the medication powder. Following DPI activation, the device must be held in an upright position and not shaken, to avoid removing the dose from the inhalation flow path. In addition, exhalation into the device, following activation, may remove the powder dose in the chamber, while humidity may compromise separation of the drug-carrier aggregate. ${ }^{36}$ Humidity may also plague storage of DPIs, particularly multi-dose reservoir devices, which rely on a desiccant and mouthpiece closure for protection. Meakin et al demonstrated a $50 \%$ reduction in the respirable fraction of each dose of the Turbuhaler device, following storage in $75 \%$ humidity at $30^{\circ} \mathrm{C}$ within 1 hour ${ }^{51}$ of 
removing the mouthpiece cap. The impact on this multi-dose reservoir inhaler was evident at 60 days following exposure. These findings stress the need for patient education measures addressing activation and storage of DPIs.

While inhalation technique for DPIs is comparable, differences in device preparation for inhalation separate the multitude of DPIs designs, potentially confusing patients and providers alike. In a prospective observational survey of 1,116 patients, Santus et al found $18 \%$ of patients spontaneously discontinued inhalers due to the complexity of therapy. ${ }^{52}$ Despite dissimilarities in appearance and preparation, patient preference for multiple dose DPIs may stem from the limited steps required for device activation. Chorao et al assessed 301 adult patients with asthma and COPD for inhaler device preference and technique. The authors compared four multiple dose DPIs, three single dose DPIs, a pMDI, and Respimat ${ }^{\mathrm{TM}}$ inhaler devices. ${ }^{53}$ The authors determined that no inhaler device demonstrated superiority in overall technique performance. However, patients reported the multiple dose DPI devices, Turbuhaler, Diskus, and Novolizer, were among the four easiest to use inhalers. Similarly, patients considered these multiple dose DPIs their favorite devices for daily use, while all single dose DPIs ranked among their least favorite inhalers. ${ }^{53}$

More recently, in an effort to further refine design and administration, introduction of the Ellipta ${ }^{\circledR}$ multiple dose DPI (SmithKlineBeecham), reduced device preparation for inhalation to a single step (Table 2). The Ellipta ${ }^{\circledR}$ DPI has demonstrated high patient satisfaction and preference over other devices including the Diskus ${ }^{\circledR}$ DPI, HandiHaler ${ }^{\circledR}$ DPI, and pMDIs in qualitative interviews among patients with asthma and COPD. ${ }^{54}$ This advancement in product usability further illustrates how patient device preference may accompany effortlessness simplicity of administration. ${ }^{54}$

\section{Nebulizers}

Medications can be administered by one of the three types of nebulizers including jet, ultrasonic, and mesh. Jet nebulizers remain the most commonly used nebulization devices in clinical practice. They generate aerosol particles as a result of the impact between a medication in solution or suspension and a stream of high speed air in the nebulizer chamber. Ultrasonic nebulizers use a rapidly vibrating piezo-electric crystal to produce aerosolized particles. ${ }^{55}$ Ultrasonic vibrations from the electric crystal are transmitted to the surface of the drug solution where standing waves are formed. Droplets break free from the crest of these waves and are released as aerosol. Mesh nebulizers utilize either active or passive mechanisms. In active systems, an aperture plate vibrates at a high frequency while solution is drawn through the openings in the plate. In a passive system, mesh is attached to a transducer horn and vibrations of a piezo-electric crystal that are transmitted via the transducer horn force the solution through the mesh to create an aerosol. ${ }^{55}$

In comparison to other aerosolized drug delivery systems, nebulizers are the easiest for patients to use and offer several advantages. ${ }^{56}$ Nebulizers require minimal handbreath coordination, hand strength, inspiratory flow, and do not require manual dexterity. ${ }^{57}$ In addition, the visible aerosol produced by nebulizers may foster confidence in patients by providing visual proof that they are receiving the medication. ${ }^{58}$ Evidence indicates that elderly patients with asthma or COPD find nebulized bronchodilators to be more effective than therapy delivered via a pMDI. ${ }^{59}$ In a small survey of patients receiving outpatient nebulizer therapy for chronic lung disease, a majority reported that nebulizer use afforded improved symptom control, well-being, and self-confidence. ${ }^{60}$

However, nebulizers have distinct shortcomings when compared to other aerosolized drug delivery systems. A glaring disadvantage of all nebulizer devices is their inefficiency. Because the principle of nebulized bronchodilator delivery is that an aerosol is generated continuously throughout a patient's respiratory cycle, a significant portion of each dose is lost as a result of exhalation. Two modifications to the jet nebulizers, termed "breath-enhanced" and "breath-actuated", enhance drug delivery in comparison to traditional jet nebulizers. The breath-enhanced jet nebulizer utilizes one-way valves to prevent the loss of medication to the environment during exhalation. ${ }^{55}$ As a patient inhales, an inspiratory valve opens allowing the aerosol to pass through the nebulizer; aerosolized medication that is exhaled passes through an expiratory valve in the nebulizer's mouthpiece where it is chambered for the patient's next inhalation. A breath-actuated jet nebulizer employs a breath-actuated valve to coordinate the generation of aerosol with inhalation. ${ }^{55}$ Nebulized drug delivery can be further maximized through adaptive aerosol delivery systems that pair software control with nebulization. ${ }^{61}$ These adaptive delivery systems synchronize the delivery of nebulized medication with a patient's breathing pattern. ${ }^{61}$ Other drawbacks of nebulizers involve device preparation, duration of administration, and maintenance. Patients must load the nebulization device with medication solution for each treatment, followed by administration time that far exceeds pMDIs and DPIs. Nebulizers need frequent cleaning to prevent bacterial contamination of the reservoir and resultant 
respiratory infections. ${ }^{62}$ Jet nebulization requires an air compressor which typically involves an external power supply. In addition to compromising portability, compressors are generally heavy and noisy. Newer nebulizer designs have enhanced patient convenience. By design, ultrasonic and mesh nebulizers more efficiently generate an aerosol and thereby shorten treatment times. Because they do not require compressed gas, ultrasonic and mesh devices are more portable and quieter than jet nebulizers, while offering the most constant delivery of medication. ${ }^{63}$ Despite these advantages, ultrasonic and mesh nebulizers do not provide improved bronchodilator efficacy in comparison to jet nebulizers, and are significantly more expensive. ${ }^{63}$ Ultrasonic nebulizers are not suitable for suspensions and their piezo-electric crystal can heat the liquid medication in the reservoir rendering it inappropriate for thermal-labile medications, ${ }^{63}$ such as budesonide. ${ }^{64}$ Mesh nebulizers require a significant amount of maintenance and cleaning after each use to prevent the accumulation of deposits and subsequent blockage of the apertures. ${ }^{63}$ With these many requirements, patients displaying limited cognitive and physical abilities require a trained provider to prepare, administer, and maintain the nebulizer device.

\section{Education challenges}

Patient education is crucial for initiating effective inhaler use, while ongoing, recurrent evaluation and education of inhaler skills are vital for sustaining appropriate technique, and inhaler selection. Twenty-one percent of adults in the USA read below the fifth grade level. ${ }^{65}$ Patient reading level is among the strongest predictors of proper inhaler technique and disease knowledge. ${ }^{66}$ Traditional patient education materials are often too complex for low literacy individuals. Accordingly, only $21 \%$ of patients were able to correctly use a pMDI after reading the package insert. ${ }^{66}$ Importantly, inadequate health literacy, as measured by Short Test of Functional Health Literacy scores $\leq 23$ (of 36), may be evident in $22 \%-36 \%{ }^{67-69}$ of patients with asthma or COPD, with an increased risk among the elderly. ${ }^{70}$ Inadequate health literacy has been associated with worsened inhaler technique and disease knowledge ${ }^{68}$ but not difficulty learning or retaining instructions. ${ }^{68,71,72}$ Patients with lower health literacy require simplified reading material (ie, seventh grade reading level ) ${ }^{69}$ and benefit from tailored physical demonstration of an inhaler technique, such as Teach-to-goal (TTG). ${ }^{67,69,72}$ TTG involves instructor demonstration of correct inhaler use, followed by assessment of patient technique. Repeated cycles of instruction and reassessment continue until the patient displays mastery of device technique, as evidenced by a prescribed checklist. ${ }^{71,72}$ TTG has demonstrated significant reduction in MDI misuse, compared with a single brief intervention, and may require 15 to 30 minutes of educational instruction. ${ }^{71,72}$ If TTG training is not possible, health care providers' use of verbal education alongside physical demonstration of each device may also improve inhaler use. ${ }^{73,74}$ Physical demonstration has been shown to significantly impact inhaler technique over verbal instruction alone, which is evident after initiation $^{75}$ and up to 4 months follow-up. ${ }^{74}$

It has been stated that management of chronic airway disease is $10 \%$ medication and $90 \%$ education. ${ }^{66}$ The cornerstone for education is knowledgeable health care providers. Failure of patients to effectively use inhaler devices can be largely attributed to deficiencies in clinicians' knowledge of inhaler technique. In a review of 20 studies, ${ }^{76} 22 \%-45 \%$ of nurses, $10 \%-28 \%$ of physicians and medical students, and $17 \%$ of pharmacists were unable to demonstrate at least $80 \%$ of correct steps for successful use of pMDI and DPI devices. These findings were recently repeated in a trial of 200 health care providers (HCPs), including physicians, nurses, pharmacists, and respiratory therapists, finding only $22.5 \%$ of clinicians demonstrated $100 \%$ correct technique among three inhaler devices. ${ }^{75}$ Education of the educator is paramount to improving the competency of health care providers on use of inhaler devices. With multiple educational platforms available, the clinician should actively seek out reputable educational venues and resources to stay abreast of new inhaler developments. However, even the most competent inhaler education efforts may wane with prolonged use of each device. While $85 \%$ of pharmacists reported educating patients on new pMDI prescriptions, $47 \%$ provided inhaler education at 3 months, while only $21 \%$ indicated they followed up with long-term users. ${ }^{77}$ Lack of recurrent instruction and evaluation may result in diminished effectiveness of inhaler technique within months of follow-up. ${ }^{78}$ Finally, to address education involving a wealth of inhaler options, clinicians and patients would benefit from a checklist of inhaler instructions to reaffirm appropriate device technique. ${ }^{79}$

\section{Adherence challenges and opportunities}

Despite effective medications for obstructive airway disease, an average of $60 \%$ of patients with COPD, and $51 \%$ of patients with asthma do not adhere to prescribed treatment. ${ }^{20-22,80}$ Medication non-adherence leads to a greater frequency and severity of respiratory symptoms, compromising quality of life, threatening hospitalizations and mortality, while raising health care costs. Reliable adherence data available to the clinician and patient would allow better informed health 
care decisions, by identifying patterns of non-adherence and their rationale. ${ }^{81}$

Assessment of adherence is generally been a result of recall through patient self-reporting or inhaler device dispensing data. ${ }^{82}$ Patient self-reporting may be inaccurate, as patients who underuse inhalers over report use, while those who overuse inhalers tend to underreport their use. ${ }^{83}$ Medication dispensing data can provide an estimate of inhaler utilization, but cannot confirm patterns of non-adherence ${ }^{84}$ and is vulnerable to medication stockpiling. ${ }^{83}$ However, the advent of electronic monitoring devices (EMDs) allows for potentially accurate and reliable assessment of adherence to inhaler devices. ${ }^{85}$ EMDs are attached to current inhalers to provide device adherence feedback to the patient through dosing prompts (ie, customizable ringtone reminders), while recording and charting adherence patterns that are uploaded to a website or cellphone for viewing. ${ }^{85-87}$ Some EMDs have expanded their role to include recording of inspiratory flow data (ie, Pneumotachograph device).$^{85}$ The majority of EMDs are intended for use with pMDIs, probably resulting from the homogeneous design of these devices. However, several EMDs exist for nebulizers, and DPI devices (ie, SmartTurbo and SmartDisk, Nexus6) ${ }^{85}$ EMDs promote adherence through two methods. The direct-to-patient reminder interface helps establish routines, increase patient engagement with the device, and improve self-management. ${ }^{88}$ In addition, EMDs provide opportunity for face-to-face discussion of adherence data, to facilitate shared decision-making (SDM) and improve treatment outcomes. ${ }^{89}$ Unfortunately, while EMDs have demonstrated significantly improved adherence to inhalers in clinical trials, this has not translated into improved clinical outcomes or reduced health care costs. ${ }^{88,90}$ This may be a result of highly motivated volunteers in the control groups, leading to increased awareness and heightened medication adherence. ${ }^{81}$ EMDs may be particularly accepted among technology savvy individuals with an appetite for personal health monitoring. ${ }^{81}$ However, the feasibility of EMDs in patients with varied medical, social, and economic obstacles, including the ability and want to use EMD, remains to be studied. ${ }^{91}$ EMDs' greatest impact would likely be demonstrated among patients with severe obstructive airway disease, ${ }^{92}$ identifying the contribution of poor inhaler adherence to disease control. Future trials examining these practice concerns, cost effectiveness, and demonstrating improved health care outcomes will help support reimbursement of EMD interventions and devices. ${ }^{85}$

Although the role of EMD monitoring of inhalers among elderly patients with chronic airway disease remains undeter- mined, follow-up clinic visits involving SDM will be pivotal in addressing inhaler adherence. A randomized control trial of 612 patients with poorly controlled asthma studied the impact of shared decision approach to care compared with "usual care", involving the stair step approach to therapy cited by guidelines. ${ }^{93,94} \mathrm{SDM}$ consists of four features including sharing relevant information, expressing treatment preferences, deliberating options, and agreeing on treatment to implement. Compared to usual care at 1 year follow-up, the SDM method resulted in significantly greater refill adherence and improved clinical outcomes including asthma-related quality of life, utilization of health care, use of rescue medications, and likelihood of well controlled asthma. The SDM approach to patient-centered care demonstrated substantial potential to change patient behavior through mutually agreed upon treatment, resulting in increased inhaler adherence and improving clinical outcomes in patients with poorly controlled asthma. ${ }^{94}$

\section{Discussion}

With an expectant population surge among individuals $>65$ years of age by 2050 , elderly patients with asthma and COPD present unique challenges to inhaler medication selection that should be opportunistically addressed by health care providers. Among the most relevant of these challenges are possible impairment to physical skills necessary for inhaler manipulation and cognitive abilities for learning inhaler techniques. Elderly patients may have reduced financial income together with increased medication needs that place constraints on health care expenditures. Patient education on appropriate use of inhaler devices may be relegated to written material with optional verbal instruction to patients often lacking necessary literacy skills, and providers lacking literacy on device administration. The omission of patient preference during device selection may challenge inhaler acceptability. Given an option of DPI and pMDI devices for both rescue and controller medications, patient preference for a device may include ease of use, convenience (ie, multiple dose inhaler), and visual or audible indicators of dosing completion. These unaddressed challenges to inhaler selection contribute to inappropriate use of inhalers in $41 \%-69 \%$ of patients with obstructive airway disease, ${ }^{78}$ with critical errors in at least $88 \%$ of patients. ${ }^{95}$ Importantly, at least $51 \%$ of patients with asthma and COPD do not adhere to their prescribed treatment. ${ }^{20-22}$

Clinicians must see these challenges as opportunities to address obstacles that undermine therapy success. Physical and cognitive abilities can be readily assessed through patient 
demonstration of device technique, identifying the need for nebulization, and additional patient care services. Clinicians should be aware of available patient financial resources in the context of polypharmacy and the Medicare gap (until 2020). Evidence of a coverage gap non-adherence had been demonstrated, especially among high cost brand dominated medications. ${ }^{26}$ Educational challenges for both patient and health care provider may result from the deluge of choices among inhaler devices. Clinicians should pursue reputable educational resources and platforms for new device development and administration. Clinicians and patient education should include a checklist for inhaler technique, while choosing a single device format (ie, DPI for rescue and controller medications) to further improve technique recall. Verbal instruction together with physical demonstration of inhaler use by the health care provider, followed by device demonstration by the patient, significantly improves inhaler administration technique. In everyday practice, health care providers must take advantage of clinical opportunities to address inhaler misuse, underuse, and overuse. In the outpatient setting, refill histories (ie, monthly rescue inhalers) suggest an ineffective role of controller medications. This clinical finding should offer motive to assess and correct inhalation technique prior to controller medication changes. Similarly, hospital admissions and emergency department visits provide an opportunity to review inhaler device technique and its contribution to each event, prior to changes in medication selection or dosing.

Electronic medical devices (EMDs) may accurately and reliably track patient adherence. These devices may provide the greatest benefit to patients with severe, poorly controlled obstructive airway disease. However, limited integration with DPI devices, cost (lack of reimbursement), and elderly patient willingness and ability to utilize EMD technology remain barriers to implementation. In clinical trials, EMDs have shown significant increases in adherence to inhaler devices. These findings may be attributable to use of face-to-face clinician patient discussion of data to promote SDM for improved treatment outcomes. Patients receiving the SDM approach demonstrated significantly improved refill adherence and clinical outcomes, including use of rescue medications, use of health care facilities, and quality of life, as compared to "usual care". ${ }^{93,94}$ SDM endorses clinician and patient deliberation on treatment preferences and options for mutual agreement on treatment decisions. Medication adherence has been defined as "the extent to which a person's behavior coincides with medical or health advice". ${ }^{20}$ Accommodating the patient treatment preferences and needs through SDM approaches to care, may ultimately address the challenges to non-adherence by affording the patient a greater role in self-care.

\section{Conclusion}

The medication challenges unique to inhalers in elderly patients with obstructive airway disease should be opportunistically addressed by health care providers. Upon initiation of therapy, assessment of patient abilities and financial resources may determine the option of inhaler devices. Clinician knowledge of available inhaler devices and their administration may initiate SDM in relation to patient device preferences among rescue and controller medications. Once selected, patient education involving device demonstration and SDM should be longstanding and opportunistic. These opportunistic measures include addressing cues to failed inhaler adherence in the outpatient setting, and the contribution of inhaler non-adherence to hospital admissions and emergency department visits.

\section{Disclosure}

No source of external funding was obtained in the creation of this manuscript. The authors report no conflicts of interest in this work.

\section{References}

1. Global Initiative for Chronic Obstructive Lung Disease. Global strategy for diagnosis, management, and prevention of COPD. GOLD. Available from: http://www.goldcopd.org/uploads/users/files/GOLD_ Report_2014_Jan23.pdf. Accessed May 18, 2015.

2. Melani AS. Management of asthma in the elderly patient. Clin Interv Aging. 2013;8:913-922.

3. Yanez A, Sang-Hoen C, Soriano JB, et al. Asthma in the elderly: what we know and what we have yet to know. World Allergy Organ J. 2014; $7(1): 8$.

4. Papaiwannou A, Zarogoulidis P, Porpodis K, et al. Asthma-chronic obstructive pulmonary disease overlap syndrome (ACOS): current literature review. J Thorac Dis. 2014;6 Suppl 1:S146-S151.

5. Krishnan V, Diette GB, Rand CS, et al. Mortality in patients hospitalized for asthma exacerbations in the United States. Am J Respir Crit Care Med. 2006,174(6):633-638.

6. Luskin AT, Chipps BE, Rasouliyan L, Miller DP, Haselkorn T, Dorenbaum A. Impact of asthma exacerbations and asthma triggers on asthma-related quality of life in patients with severe or difficult-to-treat asthma. J Allergy Clin Immunol Pract. 2014;2(5):544-552.

7. Dolovich MB, Ahrens RC, Hess DR, et al. Device selection and outcomes of aerosol therapy: evidence-based guidelines: American College of Chest Physicians/American College of Asthma, Allergy and Immunology. Chest. 2005;127(1):335-371.

8. Brocklebank D, Ram F, Wright J, et al. Comparison of the effectiveness of inhaler devices in asthma and chronic obstructive airways disease: a systematic review of the literature. Health Technol Assess. 2001; 5(26):1-149.

9. Slejko JF, Ghushchyan VH, Sucher B, et al. Asthma control in the United States, 2008-2010: indicators of poor asthma control. J Allergy Clin Immunol. 2014;133(6):1579-1587.

10. Bryant J, McDonald VM, Boyes A, Sanson-Fisher R, Paul C, and Melville J. Improving medication adherence in chronic obstructive pulmonary disease: a systematic review. Respir Res. 2013;14:109. 
11. Global Initiative for Asthma [homepage on the Internet]. Global strategy for asthma management and prevention [updated 2009]. Available from: http:/www.ginasthma.org/guidelines-gina-report-global-strategyforasthma.html. Accessed May 20, 2015.

12. Hanania NA, King MJ, Braman SS, et al. Asthma in the elderly: Current understanding and future research needs - a report of a National Institute on Aging (NIA) workshop. J Allergy Clin Immunol. 2011;128 (3 Suppl):S4-S24.

13. Allen SC, Ragab S. Ability to learn inhaler technique in relation to cognitive scores and tests of praxis in old age. Postgrad Med J. 2002;78(915):37-39

14. Allen SC, Jain M, Ragab S, Malik N. Acquisition and short-term retention of inhaler techniques require intact executive function in elderly subjects. Age Ageing. 2003;32(3):299-302.

15. Gray SL, Williams DM, Pulliam CC, Sirgo MA, Bishop AL, Donohue JF. Characteristics predicting incorrect metered-dose inhaler technique in older subjects. Arch Intern Med. 1996;156(9):984-988.

16. Armitage JM, Williams SJ. Inhaler technique in the elderly. Age Ageing.1988;17(4):275-278.

17. Khassawneh BY, Al-Ali MK, Alzoubi KH, et al. Handling of inhaler devices in actual pulmonary practice: metered-dose inhaler versus dry powder inhalers. Respir Care. 2008;53(3):324-328.

18. Charlesworth CJ, Smit E, Lee DS, Alramadhan F, Odden MC. Polypharmacy Among Adults Aged 65 Years and Older in the United States: 1988-2010. J Gerontol A Biol Sci Med Sci. 2015; 70(8):989-995.

19. Nobili A, Garatinni S, Mannucci PM. Multiple diseases and polypharmacy in the elderly; challenges for the internist of the third millennium. J Comorbidity. 2011;1:28-44.

20. Restrepo RD, Alvarez MT, Wittnebel LD, et al. Medication adherence issues in patients treated for COPD. Int J Chron Obstruct Pulmon Dis. 2008;3(3):371-384.

21. Bateman ED. Treatment adherence in asthmatic patients: the last frontier? J Allergy Clin Immunol. 2014;134(6):1269-1270.

22. Roy A, Battle K, Lurslurchachai L, Halm EA, Wisnivesky JP. Inhaler device, administration technique, and adherence to inhaled corticosteroids in patients with asthma. Prim Care Respir J. 2011; 20(2):148-154.

23. Administration on Aging. A Profile of Older Americans: 2012 Administration for Community Living. US Department of Health and Human Services. Available from: http:/www.aoa.gov/Aging_Statistics/ Profile/2012/docs/2012profile.pdf. Assessed May 23, 2015.

24. Employee Benefit Research Institute. Health Insurance and the Elderly. Available from:http:/www.ebri.org/pdf/publications/facts/0813fact. pdf. Accessed May 23, 2015.

25. Q1Medicare.com 2015 Drug Finder [homepage on the Internet]. Search for your prescription drug across all Medicare Part of Medicare Advantage Plans. ADVAIR DISKUS MIS 500/50. Available from: http://www. q1medicare.com/PartD-SearchPDPMedicarePartDDrugFinder.php?sta teReg $=140$ H\&plans $=$ Humana\&plans $2=$ AARP \&sort=\&ded=\&gap $=\&$ prem $=\&$ ndc $=00173069700 \&$ drug=ADVAIR $\% 20$ DISKU $\% 20 \mathrm{MIS} \% 20$ 500/50). Accessed May 24, 2015.

26. Joyce GF, Zissimopoulos J, Goldman DP. Digesting the doughnut hole. $J$ Health Econ. 2013;32(6):1345-1355.

27. Q1Medicare.com 2015 Drug Finder [homepage on the Internet]. Search for your prescription drug across all Medicare Part of Medicare Advantage Plans. Available from: http://www.q1medicare.com/PartDSearchPDPMedicarePartDDrugFinder.php. Accessed May 24, 2015.

28. US Department of Health and Human Services [homepage on the Internet]. The Affordable Care Act and Older Americans. US Department of Health and Human Services. Available from: http://www.hhs. gov/healthcare/facts/factsheets/2015/03/affordable-care-act-olderamericans.html\#discounts. Accessed May 25, 2015.

29. Fink JB. Metered-dose inhalers, dry powder inhalers, and transitions. Respir Care. 2000;45(6):623-635.

30. Lavorini F, Fontana GA, Usmani OS. New inhaler devices - the good, the bad and the ugly. Respiration. 2014;88(1):3-15.
31. Broeders ME, Sanchisb J, Levy ML, Cromptond GK, Dekhuijzena PN; ADMIT Working Group. The ADMIT series - issues in inhalation therapy. 2. Improving technique and clinical effectiveness. Prim Care Respir J. 2009;18(2):76-82.

32. McFadden ER Jr. Improper patient techniques with metered dose inhalers: clinical consequences and solutions to misuse. J Allergy Clin Immunol. 1995;96(2):278-283.

33. Haughney J, Price D, Barnes NC, Virchow JC, Roche N, Chrystyn H. Choosing inhaler devices for people with asthma. Current knowledge and outstanding research needs. Respir Med. 2010;104(9):1237-1245.

34. Rau JL. The inhalation of drugs: advantages and problems. Respir Care. 2005;50(3):3673-3682.

35. Sadowski CA, Cor K, Cave A, and Banh HL. Administration Technique and acceptance of inhaler devices in patients with Asthma and COPD. Ann Pharmacother. 2015;49(6):639-648.

36. Laube BL, Janssens HM, de Jongh FH, et al. What the pulmonary specialist should know about the new inhalation therapies. European Respiratory Society; International Society for Aerosols in Medicine. Eur Respir J. 2011;37(6):1308-1331.

37. Anderson P. Use of Respimat Soft Mist inhaler in COPD patients. Int J Chron Obstruct Pulmon Dis. 2006;1(3):251-259.

38. Hodder R, Reese PR, Slaton T. Asthma patients prefer Respimat Soft Mist Inhaler to Turbuhaler. Int J Chron Obstruct Pulmon Dis. 2009;4:225-232.

39. Brand P, Hederer B, Austen G, Dewberry H, Meyer T. Higher lung deposition with Respimat Soft Mist inhaler than HFA-MDI in COPD patients with poor technique. Int J Chron Obstruct Pulmon Dis. 2008;3(4):763-770.

40. Schürmann W, Schmidtmann S, Moroni P, Massey D, Qidan M. Respimat Soft Mist inhaler versus hydrofluoroalkane metered dose inhaler: patient preference and satisfaction. Treat Respir Med. 2005; 4(1):53-61.

41. Freytag F, Rau-Berger H, Glaab T, et al. Respimat ${ }^{\mathbb{B}}$ Soft Mist $^{\mathrm{TM}}$ Inhaler preferred to Diskus by patients with COPD and/or asthma. Am J Respir Crit Care Med. 2007;175:A639.

42. Islam N, Gladki E. Dry powder inhalers (DPIs) - a review of device reliability and innovation. Int J Pharm. 2008;360(1-2):1-11.

43. Newman SP. Drug delivery to the lungs from dry powder inhalers. Curr Opin Pulm Med. 2003;9 Supp1 1:S17-S20.

44. Demoly P, Hagedoorn P, de Boer AH, Frijlink HW. The clinical relevance of dry powder inhaler performance for drug delivery. Respir Med. 2014;108(8):1195-1203.

45. Janssens W, VandenBrande P, Hardeman E, et al. Inspiratory flow rates at different levels of resistance in elderly COPD patients. Eur Respir J. 2008;31(1):78-83.

46. Yang MY, Chan JG, Chan HK. Pulmonary drug delivery by powder aerosols. J Control Release. 2014;193:228-240.

47. Jarvis, S, Ind PW, Shiner RJ. Inhaled therapy in elderly COPD patients; time for re-evaluation? Age Ageing. 2007;36(2):213-218.

48. Chrystyn H. Is inhalation rate important for a dry powder inhaler? Using the In-Check Dial to identify these rates. Respir Med. 2003;97(2) $181-187$.

49. Hess DR. Metered-dose inhalers and dry powder inhalers in aerosol therapy. Respir Care. 2005;50(10):1376-1383.

50. Atkins PJ. Dry powder inhalers: an overview. Respir Care. 2005;50(10): 1304-1312.

51. Meakin BJ, Cainey J, Woodcock PM. Effect of exposure to humidity on terbutaline delivery from Turbuhaler dry powder inhalation devices. Eur Respir J. 1993;6(5):760-761.

52. Santus P, Picciolo S, Proietto A, et al. Doctor-patient relationship: a resource to improve respiratory diseases management. Eur J Intern Med. 2012;23(5):442-446.

53. Chorão P, Pereira AM, Fonseca JA. Inhaler devices in asthma and COPD - an assessment of inhaler technique and patient preferences. Respir Med. 2014;108(7):968-975.

54. Svedsater H, Dale P, Garrill K, Walker R, Woepse MW. Qualitative assessment of attributes and ease of use of the ELLIPTA ${ }^{\mathrm{TM}}$ dry powder inhaler for delivery of maintenance therapy for asthma and COPD. BMC Pulm Med. 2013;13:72. 
55. Hess DR. Nebulizers: principles and performance. Respir Care. 2000;45(6):609-622.

56. Rau JL. Practical problems with aerosol therapy in COPD. Respir Care. 2006;51(2):158-172.

57. Filuk R. Delivery system selection: clinical considerations. Am Health Drug Benefits. 2008;1(Suppl 8):13-17.

58. Geller DE. Comparing clinical features of nebulizer, metered-dose inhaler, and dry powder inhaler. Respir Care. 2005;50(10):1313-1321.

59. Balzano G, Battiloro R, Biraghi M. Effectiveness and acceptability of domiciliary multidrug inhalation treatment in elderly patients with chronic airflow obstruction: metered dose inhaler versus jet nebulizer. J Aerosol Med. 2000;13(1):25-33.

60. Barta SK, Crawford A, Roberts CM. Survey of patients' views of domiciliary nebuliser treatment for chronic lung disease. Respir Med. 2002;96(60):375-381.

61. Nikander K. Adaptive aerosol delivery: the principles. Eur Respir Rev. 1999;7:385-389.

62. Cobben NA, Drent M, Jonkers M, Wouters EF, Vaneechoutte M, Stobberingh EE. Outbreak of severe Pseudomonas aeruginosa respiratory infections due to contaminated nebulizers. $J$ Hosp Infect. 1996;33(1):63-70.

63. Dolovich MB, Dhand R. Aerosol drug delivery: developments in device design and clinical use. Lancet. 2011;377(9770):1032-1045.

64. Pulmicort (budesonide) [package insert]. Wilmington, DE: AstraZeneca LP; 2009.

65. Kirsch IS, Jungebut A, Jenkins L, Kolstad A. National Center for Education Statistics. Adult literacy in America. A first look at the findings of the National Adult Literacy Survey. 3rd ed. US Department of Education, Office of Educational Research and Improvement; 2002.

66. Fink JB, Rubin BK. Problems with inhaler use: a call for improved clinician and patient education. Respir Care. 2005;50(10): 1360-1374.

67. Press VG, Arora VM, Shah LM, et al. Teaching the use of respiratory inhalers to hospitalized patients with asthma or COPD: a randomized trial. J Gen Intern Med. 2012;27(10):1317-1325.

68. Paasche-Orlow MK, Riebert KA, Bilderback A, et al. Tailored education may reduce health literacy disparities in asthma self-management. $\mathrm{Am}$ J Respir Crit Care Med. 2005;172(8):980-986.

69. Kiser K, Jonas D, Warner Z, Scanlon K, Shilliday BB, DeWalt DA. A randomized controlled trial of a literacy-sensitive self-management intervention for chronic obstructive pulmonary disease patients. J Gen Intern Med. 2011;27(2):190-195.

70. Baker DW, Gazmararian JA, Sudano J, Patterson M. The association between age and health literacy among elderly persons. $J$ Gerontol B Psychol Sci Soc Sci. 2000;55(6):S368-S374.

71. Williams MV, Baker DW, Honig EG, Lee TM, Nowlan A. Inadequate literacy is a barrier to asthma knowledge and self-care. Chest. 1998;114(4):1008-1015.

72. Press VG, Arora VM, Shah LM, et al. Misuse of respiratory inhalers in hospitalized patients with asthma or COPD. J Gen Intern Med. 2011;26(6):635-642.

73. Crane MA, Jenkins CR, Goeman DP, Douglass JA. Inhaler device technique can be improved in older adults through tailored education: findings from a randomised controlled trial. NPJ Prim Care Respir Med. 2014;24:14034.

74. Bosnic-Anticevich SZ, Sinha H, So S, Reddel HK. Metered-dose inhaler technique: the effect of two educational interventions delivered in community pharmacy over time. J Asthma. 2010;47(3):251-256.

75. Basheti IA, Reddel HK, Armour CL, Bosnic-Anticevich SZ. Counseling about turbuhaler technique: needs assessment and effective strategies for community pharmacists. Respir Care. 2005;50(5):617-623.
76. Self TH, Arnold LB, Czosnowski LM, Swanson JM, Swanson H. Inadequate skill of healthcare professionals in using asthma inhalation devices. J Asthma. 2007;44(8):593-598.

77. Erickson SR, Landino HM, Zarowitz BJ, Kirking DM. Pharmacists' understanding of patient education on metered-dose inhaler technique. Ann Pharmacother. 2000;34(11):1249-1256.

78. Johnson DH, Robart P. Inhaler technique of outpatients in the home. Respir Care. 2000;45(10):1182-1187.

79. Newman SP. Inhaler treatment options in COPD. Eur Respir Rev. 2005;14(96):102-108.

80. Foster JM, Usherwood T, Smith L, et al. Inhaler reminders improve adherence with controller treatment in primary care patients with asthma. J Allergy Clin Immunol. 2014;134(6):1260-1268.

81. Chan AH, Harrison J, Black PN, Mitchell EA, Foster JM. Using electronic monitoring devices to measure inhaler adherence: a practical guide for clinicians. J Allergy Clin Immunol Pract. 2015;3(3): 335-349.

82. Bender B, Wamboldt FS, O'Connor SL, et al. Measurement of children's asthma medication adherence by self report, mother report, canister weight, and Doser CT. Ann Allergy Asthma Immunol. 2000; 85(5):416-421.

83. Patel M, Perrin K, Pritchard A, et al. Accuracy of patient self-report as a measure of inhaled asthma medication use. Respirology. 2013; 18(3):546-552.

84. Williams LK, Joseph CL, Peterson EL, et al. Patients with asthma who do notfill their inhaled corticosteroids: a study of primary nonadherence. J Allergy Clin Immunol. 2007;120(5):1153-1159.

85. Chan AH, Reddel HK, Apter A, Eakin M, Riekert K, Foster JM. Adherence monitoring and e-health: how clinicians and researchers can use technology to promote inhaler adherence for asthma. J Allergy Clin Immunol Pract. 2013;1(5):446-454.

86. Rand CS, Sevick MA. Ethics in adherence promotion and monitoring. Control Clin Trials. 2000;21(5 Suppl):S241-S247.

87. Nikander K, Turpeinen M, Pelkonen AS, Bengtsson T, Selroos O, Haahtela T. True adherence with the Turbuhaler in young children with asthma. Arch Dis Child. 2011;96(2):168-173.

88. Vervloet M, Linn AJ, van Weert JC, de Bakker DH, Bouvy ML, van Dijk L. The effectiveness of interventions using electronic reminders to improve adherence to chronic medication: a systematic review of the literature. J Am Med Inform Assoc. 2012;19(5):696-704.

89. McNamara PS, McCormack P, McDonald AJ, Heaf L, Southern KW. Open adherence monitoring using routine data download from an adaptive aerosol delivery nebuliser in children with cysticfibrosis. $J$ Cyst Fibros. 2009;8(4):258-263.

90. Black P, Garratt E, Noonan L, Arandjus C, Salmon B, Sutherland G. An inhaler with ringtones improves compliance with inhaled steroids in childhood asthma. Am J Respir Crit Care Med. 2008;117:A615.

91. Bender BG. Advancing the science of adherence measurement: implications for the clinician. J Allergy Clin Immunol Pract. 2013; 1(1):92-93.

92. Weinstein AG. Asthma adherence management for the clinician. J Allergy Clin Immunol Pract. 2013;1(2):123-128.

93. National Asthma Education and Prevention Program. Expert Panel Report-3: Guidelines for the Diagnosis and Management of Asthma. NIH Publication No 08-4051. Bethesda, MD: National Institutes of Health, National Heart, Lung, and Blood Institute; 2007.

94. Wilson SR, Strub P, Buist AS, et al. Shared treatment decision making improves adherence and outcomes in poorly controlled asthma. Am J Respir Crit Care Med. 2010;181(6):566-577.

95. Vanderman AJ, Moss JM, Bailey JC, Melnyk SD, Brown JN. Inhaler misuse in an older adult population. Consult Pharm. 2015;30(2):92-100. 


\section{Publish your work in this journal}

Patient Intelligence is an international, peer-reviewed, open access journal that characterizes and measures the central role of patient behavior and intention in optimizing healthcare management in all areas of disease and complaint types. An improved understanding of patient intelligence coupled with predictive analysis helps an organization contribute more effectively to achieving better outcomes.

Submit your manuscript here: http://www.dovepress.com/patient-intelligence-journal
Dovepress

The journal is characterized by the rapid reporting of reviews, original research, methodologies, analytics, modeling, clinical studies and patient surveys across all disease areas. The manuscript management system is completely online and includes a very quick and fair peer-review system. Visit http://www.dovepress.com/ testimonials.php to read real quotes from published authors. 